\title{
CLINICO-PATHOLOGIC CONFERENCES \\ Diffuse pulmonary ossification as a rare cause of interstitial lung disease
}

\author{
Andrew Burkett $M D^{1}$, Niamh Coffey $M D^{2}$, Nha Voduc $M D^{1}$
}

\begin{abstract}
A Burkett, N Coffey, N Voduc. Diffuse pulmonary ossification as a rare cause of interstitial lung disease. Can Respir J 2014;21(1):23-24.

Diffuse pulmonary ossification (DPO) is a rare form of interstitial lung disease. The present article describes a case of DPO in an elderly man who presented with progressive dyspnea on exertion and an isolated reduction in diffusing capacity for carbon monoxide. DPO may occur as sequelae of mitral stenosis, left heart failure, idiopathic pulmonary fibrosis, recurrent aspiration pneumonia, solid organ transplant, adult respiratory distress syndrome or may arise idiopathically. In the absence of other findings of interstitial lung disease, a lung biopsy is unlikely to be helpful in the management of these patients.
\end{abstract}

Key Words: Computed tomography; Interstitial lung disease; Pulmonary ossification; Restrictive lung disease

\section{Learning objectives}

- To understand the radiological and histopathological appearance of diffuse pulmonary ossification (DPO).

- To review the conditions associated with DPO.

CanMEDS Competency: Medical Expert

Pretest

- What conditions are associated with DPO?

- Should patients with DPO routinely be referred for lung biopsy?

- What are the treatment options for DPO?

\section{CASE PRESENTATION}

In August 2012, an 82-year-old man was referred for assessment due to a two-year history of progressive dyspnea on exertion and a chest radiograph revealing bilateral interstitial infiltrates.

His medical history was significant for mild Alzheimer's dementia, mild peripheral arterial disease, hypertension, dyslipidemia, type II diabetes mellitus, transient ischemic attack, hypothyroidism, benign prostatic hyperplasia and ulcerative colitis. His surgical history was significant for a partial gastrectomy and vagotomy for gastric ulcers in 1969, colectomy with ileostomy in 1995 and transurethral resection of the prostate in 2010. His medications included pantoprazole $40 \mathrm{mg}$, domperidone $10 \mathrm{mg}$, levothyroxine $105 \mu \mathrm{g}$, ramipril $5 \mathrm{mg}$, simvastatin $40 \mathrm{mg}$, donepezil $10 \mathrm{mg}$ and tamsulosin $4 \mathrm{mg}$ (all daily). Despite his extensive history, this man was relatively high functioning, lived alone and was independent for his activities of daily living. He continued to walk daily but became dyspneic after 5 min of walking at a brisk pace on level ground. He had a mild, nonproductive cough and had never experienced chest pain or hemoptysis.

The patient quit smoking in 1986 and smoked two packs per day from 16 to 56 years of age (corresponding to an 80 pack-year smoking history). He worked as a truck driver and denied workplace or hobby exposures. Family history was noncontributory.

His physical examination was unremarkable, with an oxygen saturation of $100 \%$ on room air, no clubbing, normal jugular venous pulse, normal heart sounds with no murmurs or evidence of pulmonary hypertension, and no peripheral edema. On lung auscultation, faint inspiratory crackles were heard at the bases.

\section{L'ossification pulmonaire diffuse, une cause rare de maladie pulmonaire interstitielle}

L'ossification pulmonaire diffuse (OPD) est une forme rare de maladie pulmonaire interstitielle. Le présent article décrit un cas d'OPD chez un homme âgé qui a consulté en raison d'une dyspnée progressive à l'effort et d'une réduction isolée de la capacité de diffusion du monoxyde de carbone. L'OPD peut être une séquelle de la sténose mitrale, de l'insuffisance cardiaque gauche, de la fibrose pulmonaire idiopathique, de la pneumonie d'aspiration récurrente, de la transplantation d'un organe plein ou de la détresse respiratoire chez l'adulte et peut aussi être un problème idiopathique. En l'absence d'autres manifestations de maladie pulmonaire interstitielle, une biopsie du poumon est peu susceptible d'être utile dans la prise en charge de ces patients.

Pulmonary investigations included pulmonary function tests (PFTs) and chest computed tomography (CT). PFTs performed in April 2012 demonstrated a total lung capacity of 4.91 L (97\% predicted), a forced vital capacity (FVC) of $2.99 \mathrm{~L}$ ( $84 \%$ of predicted [nor$\mathrm{mal} \geq 80 \%]$ ), and a forced expiratory volume in $1 \mathrm{~s}\left(\mathrm{FEV}_{1}\right)$ of $2.29 \mathrm{~L}$ ( $92 \%$ of predicted [normal $\geq 80 \%$ ]); there was no evidence of airflow obstruction, with an $\mathrm{FEV}_{1} / \mathrm{FVC}$ ratio of $76 \%$ (normal $\geq 70 \%$ ). His diffusing capacity for carbon monoxide (DLCO) was reduced (64\% predicted [normal $\geq 70 \%]$ ).

Previous chest radiographs from 2004 showed no abnormalities. CT of the thorax performed in October 2012 showed moderate to severe centrilobular and paraseptal emphysema, with evidence of air trapping and extensive subpleural reticulations that were ossified in the peripheral aspect of the mid and lower lung zones with absence of ground glass, honeycombing or architectural distortion (Figure 1).

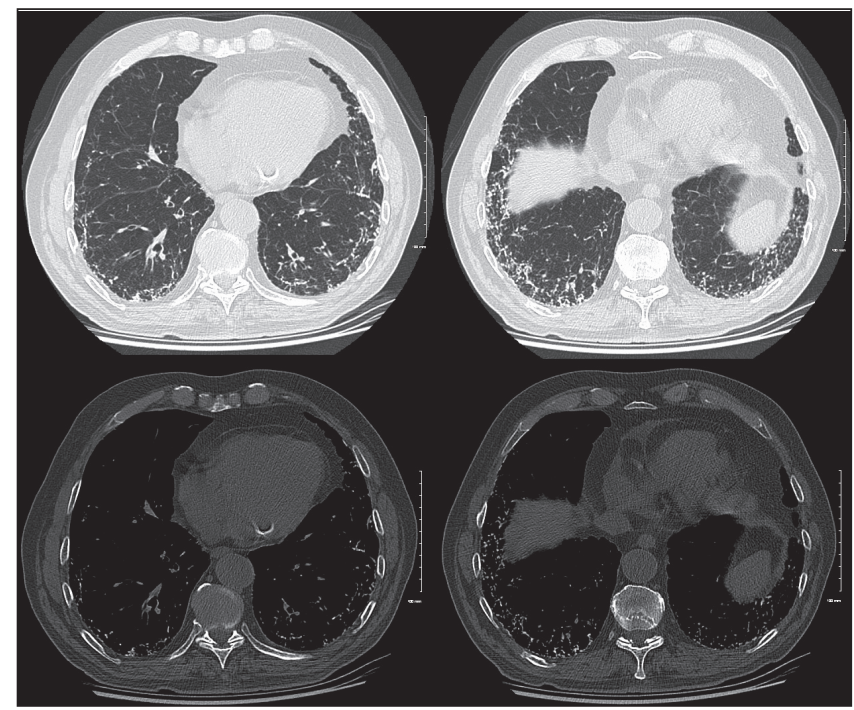

Figure 1) High-resolution computed tomography of the lung with two representative slices demonstrating extensive subpleural reticulations with bony attenuation in both lung and bone windows

${ }^{1}$ Division of Respiratory Medicine; ${ }^{2}$ Department of Medical Imaging, The Ottawa Hospital, Ottawa, Ontario

Correspondence: Dr Andrew Burkett, Division of Respiratory Medicine, The Ottawa Hospital, 501 Smyth Road, Ottawa, Ontario K1H 8L6.

Telephone 613-897-5823, fax 613-737-8537, e-mail aburkett@toh.on.ca 
Despite no spirometric evidence of airflow obstruction, it was not clear how much of the patient's dyspnea or decreased DLCO was due to emphysema verses the interstitial lung disease (ILD). No changes were made to the patient's care at that time. Repeat pulmonary function testing one year later showed a slight reduction in his DLCO to $54 \%$ predicted.

Based on the clinical presentation, PFTs and CT results, the patient was diagnosed with idiopathic diffuse pulmonary ossification. A lung biopsy was not believed to be helpful in the case.

\section{DISCUSSION}

Historically, DPO was most commonly described in the setting of severe, longstanding mitral stenosis (1-3). More recently, DPO is still commonly associated with mitral stenosis (4) but has also been described in left heart failure (5), idiopathic pulmonary fibrosis (6), recurrent aspiration pneumonia (7), post-solid organ transplant (8), post-adult acute respiratory distress syndrome (9) or idiopathically (5). Given the very low prevalence of DPO, these potential associations could be coincidental rather than reflecting any specific causality.

DPO is most commonly apparent as a rare autopsy finding (10); however, with advances in CT technology and the widespread use of $\mathrm{CT}$ in lung disease, DPO is becoming a more frequent imaging diagnosis (11). The natural history of this condition is not well described, although one report described a case with 14 years of follow-up in which the imaging findings progressed significantly but the patient's symptoms and PFT abnormalities progressed minimally (12). Because of this and expert opinion, DPO is believed to be indolent or slowly progressive (13). Interestingly, type II diabetes mellitus has been reported to have possible association with DPO (13), although this has not been studied.

The radiographic findings of DPO consist of mature bone in the periphery and basal portions of the lung, best appreciated on the osteoporosis or bone windows in thin-section CT $(11,14)$. In the setting of fibrotic ILD on CT, the presence of DPO makes the diagnosis of usual interstitial pneumonia more likely than fibrotic nonspecific interstitial pneumonia (11).

Histopathologically, DPO is often divided into two subtypes: dendriform, in which the lesions branch along terminal airways and may contain islands of marrow; or nodular, in which lesions are found in the alveolar spaces (15). Although DPO can be suggested by transbronchial biopsy if tissue samples show bone fragments, transbronchial biopsy samples are usually not large enough to demonstrate marrow elements and, therefore, open-lung or video-assisted thoracic biopsy remains the gold standard for making a histiological diagnosis (13). Previously, it had been suggested that the dendriform and nodular subtypes may help to narrow the etiology (16), but it is now known that either subtype may occur for a given etiology or that the subtypes can even occur together (5). The pathophysiology is incompletely understood; however, hypercalcemia, a local alkaline environment and previous lung injury resulting in scar are believed to be risk factors for DPO (5).

It is important to recognize DPO as a cause of ILD to alert the clinician to assess for potential associations (mitral stenosis, heart failure or aspiration pneumonia) and to avoid proceeding with lung biopsy if there are no other features of lung disease. There is no known treatment, and neither low-calcium diets or systemic steroid therapy has been shown to be helpful (5). Warfarin and bisphosphonates have been proposed as future potential therapies for DPO but these have not been studied (13).

\section{CONCLUSION}

The present report described DPO as an unusual cause of ILD and an isolated reduction in DLCO on pulmonary function testing. Clinicians should screen for associated conditions and avoid lung biopsy if there are no other features of lung disease.

\section{Post-test}

- What conditions are associated with DPO?

Most commonly mitral stenosis. Other conditions include left heart failure, idiopathic pulmonary fibrosis, recurrent aspiration pneumonia, post-solid organ transplant and post-acute respiratory distress syndrome.

- Should patients with DPO routinely be referred for lung biopsy?

In the absence of other changes of ILD (fibrosis, architectural distortion or ground-glass opacities), a biopsy is unlikely to be helpful.

- What are the treatment options for DPO?

Apart from treating associated conditions that could play a causative roll in DPO, no treatments have currently been shown to be beneficial.

\section{REFERENCES}

1. Lawson H. Disseminated ossification of lungs in mitral stenosis. BMJ 1949;1:433-4.

2. Elkeles A. Disseminated ossified nodules in the lungs associated with mitral stenosis. Proc Royal Soc Med 1947;40:405-8.

3. Whitaker W, Black A, Warrack A. Pulmonary ossification in patients with mitral stenosis. J Fac Radiol 1955;7:29-34.

4. Woolley K, Stark P. Pulmonary parenchymal manifestations of mitral valve disease. Radiographics 1999;19:965-72.

5. Chan ED, Morales DV, Welsh CH, McDermott MT, Schwarz MI. Calcium deposition with or without bone formation in the lung. Am J Respir Crit Care Med 2002;165:1654-69.

6. Crisosto CF. Diffuse pulmonary ossification associated with idiopathic pulmonary fibrosis. Archivos de Bronconeumol 2004;40:595-8.

7. Battal B, Kocaoğlu M, Ors F, Vurucu S. Massive pulmonary ossification due to recurrent aspiration pneumonia. Diagn Intervention Radiol 2009;15:212-4.

8. Kotloff RM, Ahya VN, Crawford SW. Pulmonary complications of solid organ and hematopoietic stem cell transplantation. Am J Respir Crit Care Med 2004;170:22-48.

9. Fried ED, Godwin TA. Extensive diffuse pulmonary ossification. Chest 1992;102:1614-5.

10. Lara JF, Catroppo JF, Kim DU, Da Costa D. Dendriform pulmonary ossification, a form of diffuse pulmonary ossification: Report of a 26-year autopsy experience. Arch Pathol Lab Med 2005;129:348-53.

11. Kim T, Han J, Chung M, Chung M, Choi Y. Disseminated dendriform pulmonary ossification associated with usual interstitial pneumonia: Incidence and thin-section CT - pathologic correlation. Eur Radiol 2005;15:1581-5.

12. Ahari J, Delaney M. Dendriform pulmonary ossification: A clinical diagnosis with 14 year follow-up. Chest 2007;132:4 (Meeting Abstracts).

13. Peros-Golubicić T, Tekavec-Trkanjec J. Diffuse pulmonary ossification: An unusual interstitial lung disease. Curr Opin Pulmon Med 2008;14:488-92.

14. Gevenois P, Abehsera M. Disseminated pulmonary ossification in end-stage pulmonary fibrosis: CT demonstration. Am J Roentgenol 1994;162:1303-4.

15. Konoglou M, Zarogoulidis P, Baliaka A, et al. Lung ossification: An orphan disease. J Thorac Dis 2013;5:101-4.

16. Mendeloff J. Disseminated nodular pulmonary ossification in the Hamman-Rich lung. Am Rev Respir Dis 1971;103:269-74. 


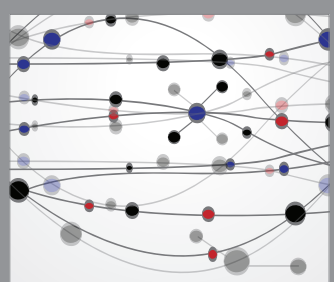

The Scientific World Journal
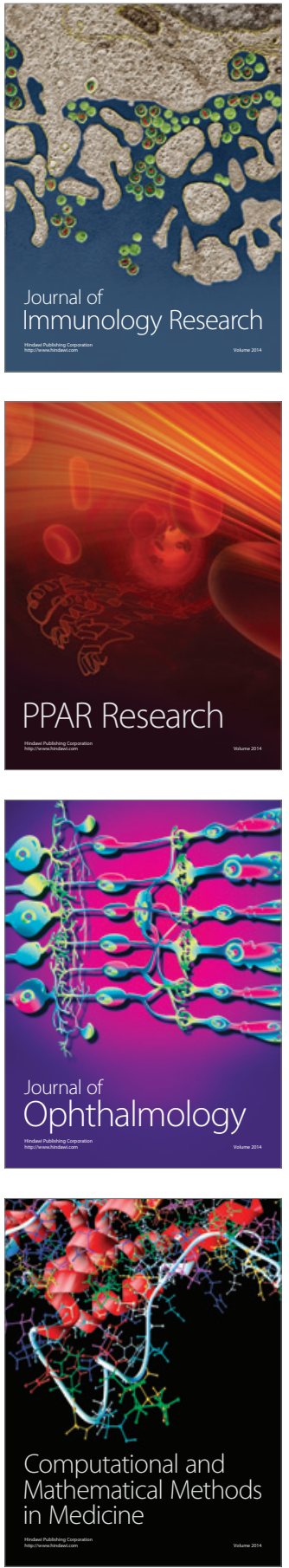

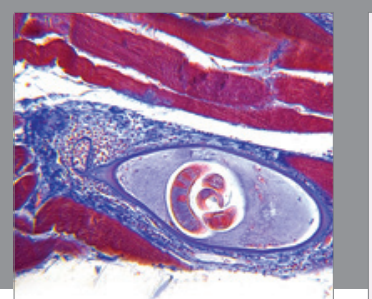

Gastroenterology Research and Practice

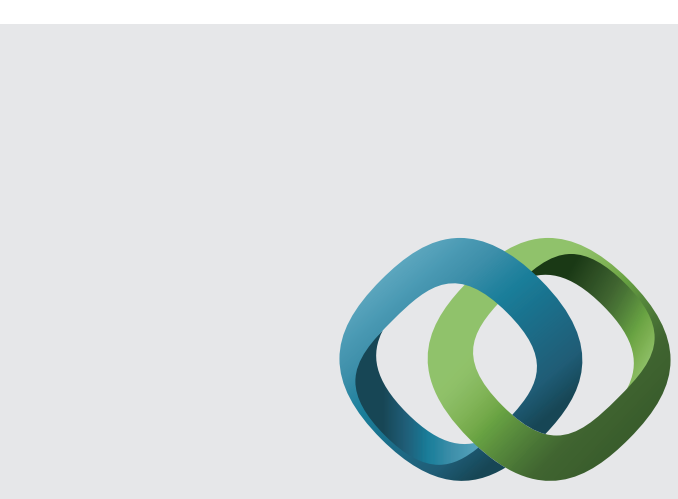

\section{Hindawi}

Submit your manuscripts at

http://www.hindawi.com
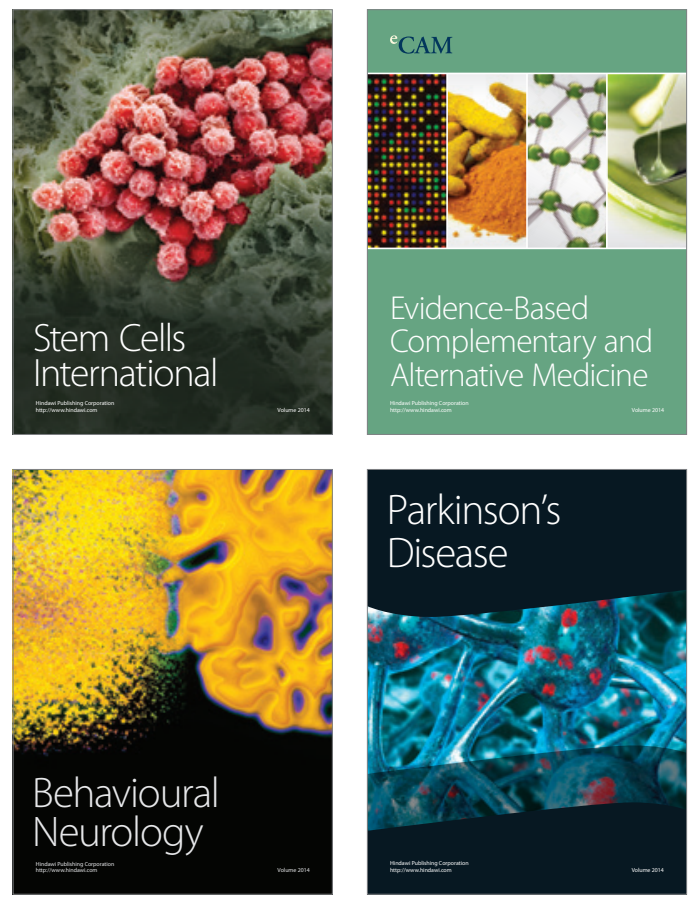
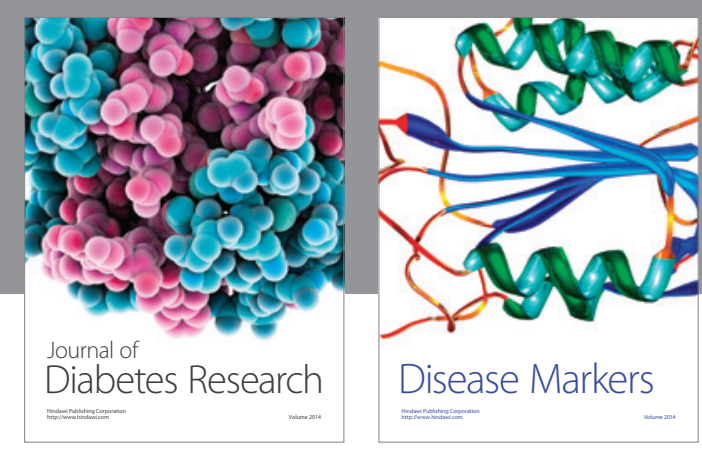

Disease Markers
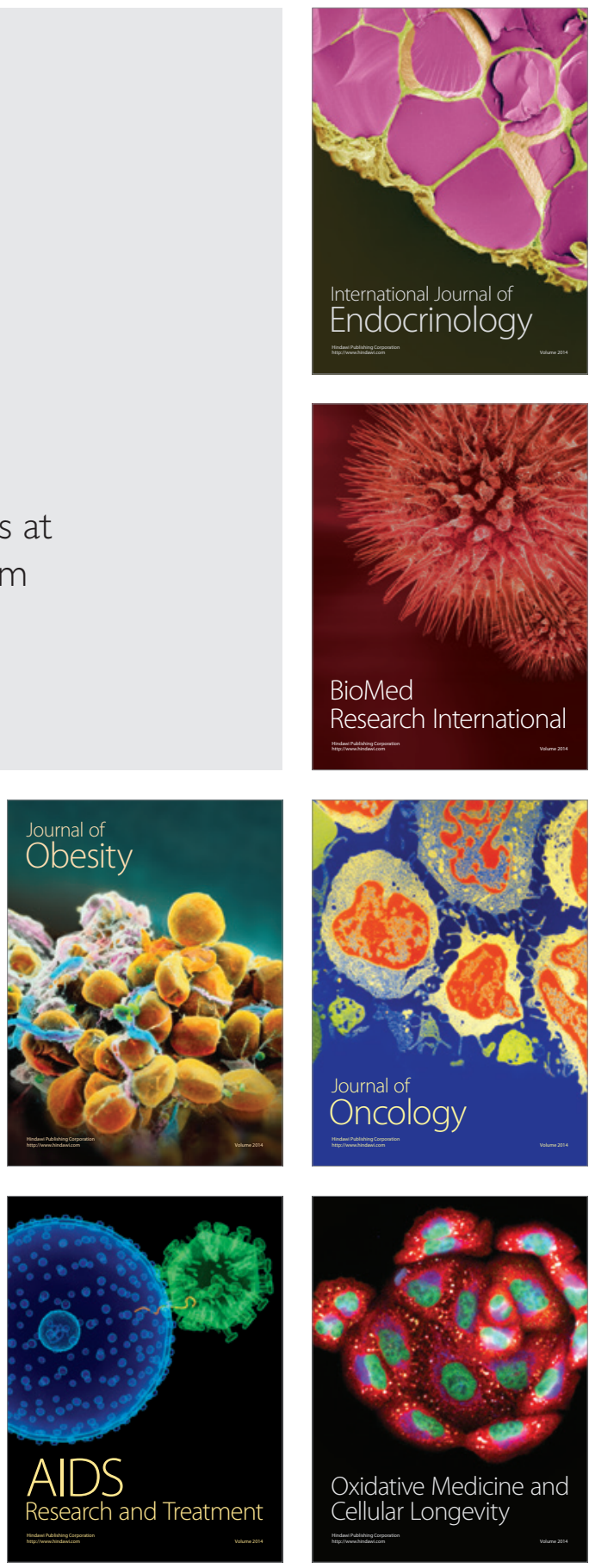